\title{
Comparison of subscription access and open access obstetrics and gynecology journals in the SCImago database
}

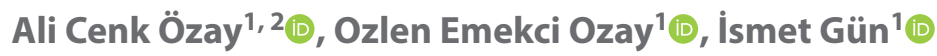 \\ ${ }^{1}$ Department of Obstetrics and Gynecology, Faculty of Medicine, Near East University, Nicosia, Cyprus \\ ${ }^{2}$ Research Center of Experimental Health Sciences, Near East University, Nicosia, Cyprus
}

\begin{abstract}
Objectives: The aim of this study is to compare the annual SJR and to evaluate the other parameters that show the scientific effect of journals in terms of open access (OA) or subscription access (SA) in the field of obstetrics and gynecology according to the SCImago database.

Material and methods: This study was conducted between September-December 2019 at Near East University. The SCImago Journal \& Country Rank database was used to collect information about the journals. We evaluated and compared the changes in the one-year SJR (SCImago Journal Rank) and journal impact factor (JIF) of OA and SA journals.

Results: Data from 183 scientific journals in the field of obstetrics and gynecology from the period between 1999 and 2018 were evaluated, where 140 of these journals were SA and 43 were OA. The average SJR of OA journals in 1999 was 0.17 , while it was 0.38 for SA journals. In 2018, these values were 0.31 and 0.78 for OA and SA journals, respectively. In the comparison of JIF, the average of the OA journals in 1999 was 0.09 , while it was 0.66 for SA journals. In 2018, these values were 0.80 and 1.93 for $\mathrm{OA}$ and $\mathrm{SA}$ journals, respectively.

Conclusions: Access to information has become easier due to technological developments and this will continue to affect the access policies of journals. Despite the disadvantages of predator journals, the rise of OA journals in terms of number and quality is likely to continue.
\end{abstract}

Key words: open access journal; impact factor; subscription access journal; SCImago; obstetrics; gynecology

\section{INTRODUCTION}

Access to information was more limited when the only option was paper journals. As a result of the widespread use of the internet, scientific publications have evolved from paper-printed to digital publications. Scientific journals are among the most frequently used sources by academicians for accessing information. Although accessing information from scientific journals via the internet can be a fast process, it may not always be easy for various reasons. The most important reason for this is that some journals ask for a subscription and apply a charge to share articles with readers. Traditional, older journals often tend to have subscription access policies, while new journals tend to be open access (OA). Today, while the majority of journals are subscription access $(\mathrm{SA})$, the number of $\mathrm{OA}$ journals is also increasing [1].
In OA journals, free access for readers is an advantage, while for authors publication fees (APC) are reported to be a disadvantage. Studies have suggested that more articles are downloaded from these journals and the number of citations to the articles in such journals is higher [2-6]. Other studies have indicated that access to the full text of the studies increases transparency and that everyone has the ability to access evidence-based information. They also claim that it protects against incomplete information received from articles in SA journals that can only be read in summary form if payment is not made $[7,8]$. It has been stated that articles published in OA journals are $90 \%$ more likely to be read and $42 \%$ more likely to be downloaded [9]. However, the debate on the seriousness of article reviews of open access journals and predatory journals continues $[10,11]$. 
The evaluation indices used to determine the quality of journals have an impact on the authors' choice of journals in the process of submitting their articles. The best known of these is the Impact Factor (IF) put forward by Garfield [12]. The IF of a journal depends on two items: the numerator and denominator. The numerator is the ratio of the number of citations in the current year to the number of publications in the previous two years and the dominator is the number of essential articles and reviews published in the same two years [12]. The SCImago database, which was developed by using the Scopus data source created by Elsevier and is the largest database for multidisciplinary scientific literature, provides detailed information on many issues, including citations of scientific journals, number of documents and impact factors by years. Unlike the Web of Science database, which uses the Journal Impact Factor (JIF) for evaluating the scientific effect of journals, self-citation is not included in the calculation of the impact factor specified in the SCImago database, which is referred to as the SCImago Journal Rank indicator (SJR) [13]. This may make the SJR more valuable over time.

We hypothesize that since authors have easier access to OA journals, the difference in the increase ratio for the metrics showing the effect of journals (SJR, JIF etc.) by the years are likely to be higher than the SA journals. In this study, we aimed to compare the annual SJR and to evaluate the other parameters that show the scientific effect of journals in terms of OA or SA in the field of obstetrics and gynecology according to the SCImago database.

\section{MATERIAL AND METHODS}

This study was conducted between September 2019 and December 2019 at the Near East University Faculty of Medicine. The SCImago Journal \& Country Rank and Web of Science (WOS) databases were used to collect information about the journals. We evaluated and compared the changes in one-year (SJR), two-year (JIF) and three-year impact factors (3-year IF) of OA and SA journals. In addition, we compared the OA and SA journals by recording the total number of self-citations, total citations, non-citable and citable documents, uncited and cited documents in the last three years (2016, 2017 and 2018) as well as the h-index. To calculate the total number of self-citations, total citations, non-citable and citable documents, uncited and cited documents per journal, we divided these parameters' values by the number of journals for each group. These parameters were also assessed again for OA and SA journals after dividing the OA group into two, namely APC requesting (Open access paid-OAP) and non-requesting (Open access free-OAF). We also examined the number of journals by years and the correlation between the APC and SJR of OAP journals. The currencies of the journals requesting payment in a cur- rency other than the US dollar (USD) were converted into US dollars at the current exchange rate and their data were recorded. The percentage changes of SJR, JIF and 3-year IF of OA and SA journals were examined. These parameters were also assessed for OAP vs OAF vs SA groups. It was also examined whether all journals were scanned in the WOS database. If a journal was indexed, the category to which it belongs was noted (Science citation index expanded (SCI-EX), Social sciences citation index ( $\mathrm{SSCl}$ ), Emerging science citation index $(\mathrm{ESCl})$.

SJR value shows the influence, impact or prestige of the journal. It demonstrates the average number of weighted citations received in the selected year by the articles published in the journal in the three previous years. SJR is calculated based on a sophisticated formula that includes three different steps in which many factors such as journal numbers, citations and references are included [14].

The journal impact factor (JIF) is a value of the frequency with which the "average article" in a journal has been cited in a specific year or period. Therefore, the impact factor of a journal is determined by dividing the number of present year citations to the source items printed in that journal during the previous two years [15]. The two-year impact factors given in the SCImago database are equivalent to the Thomson Reuters journal impact factors (JIF) [16].

The $h$-index is described by the highest value of $h$ such that the given author/journal has published $h$ articles that have each been cited at least $h$ times [17]. The total citation is the sum of all citations made to a journal's publications in the last three years and self-citation is the number of citations from a journal to articles published in the same journal. Not all articles cited in a journal may be citable. For example, research articles, conference papers and reviews are evaluated as citable, while all others are considered non-citable. A cited document is defined as an article published in a journal in the last three years and cited at least once in subsequent years, while uncited documents are defined as those that are not cited. These data are used in the SCImago database to demonstrate the scientific value and impact of the journal [16].

\section{Statistical analysis}

For statistical analysis, Statistical Program for Social Sciences (SPSS) version 16 was used. Shapiro-Wilk and Kolmogorov Smirnov tests were performed to check the conformity to normal distribution. The student $t$ test was used for the comparison of two independent groups suitable for normal distribution, and one-way ANOVA was used for comparing three or more groups. The Mann Whitney $U$ test was used in paired groups that were not normally distributed and the Kruskal Wallis test was used for three or more comparisons for groups that were not normally distributed. 
The post hoc Tukey test was used for paired comparisons after ANOVA, while the Mann Whitney $U$ test with Bonferroni correction was used after the Kruskal Walls test. The Chi-square test was used for the comparison of categorical variables. For correlation, the Pearson Correlation test was used as parametric test in groups with normal distribution, while the Spearman Correlation test was used as a nonparametric test in groups that did not comply with normal distribution. A p value less than 0.05 was considered as statistically significant.

\section{RESULTS}

In this study, the data of 183 journals were analyzed, where 140 were subscription access and 43 were open access. From 140 SA journals, 106 of them were indexed in WOS. From these 106 journals, 71 were SCI-EX, 6 were $\mathrm{SSCl}, 7$ were $\mathrm{SCl}-\mathrm{EX}+\mathrm{SSCl}$, and 22 were $\mathrm{ESCl}$. From $43 \mathrm{OA}$ journals, 27 of them were indexed in WOS, of which 9 were
$\mathrm{SCl}-\mathrm{EX}, 1$ was $\mathrm{SSCl}, 2$ were $\mathrm{SCl}-\mathrm{EX}+\mathrm{SSCl}$, and 15 were $\mathrm{ESCl}$. The number of OA journals indexed in the SCImago database in 1999 was seven, and this increased to 43 in 2018 . For SA journals, eight were indexed in 1999 and this rose to 140 in 2018. In this process, the number of OA journals increased by 13.5 -fold, while the number of SA journals increased by approximately 1.5 -fold. The average SJR of OA journals in 1999 was 0.17 , while it was 0.38 for SA journals. In 2018, these values were 0.31 and 0.78 for $O A$ and SA journals, respectively (Tab. 1). In the comparison of JIF, the average for OA journals in 1999 was 0.09 , while it was 0.66 for SA journals. In 2018, these values were 0.80 and 1.93 for OA and SA journals, respectively (Tab. 1). When the three-year average impact factor values were analyzed, the average value of OA journals was 0.17 in 1999 and it was 0.74 for SA journals. In 2018, these values were 0.78 and 2.04 for OA and SA journals, respectively (Tab. 1). According to these results, for the years analyzed, SJR, JIF

\begin{tabular}{|c|c|c|c|c|c|c|}
\hline & \multicolumn{2}{|c|}{ SJR } & \multicolumn{2}{|c|}{ JIF } & \multicolumn{2}{|c|}{ 3-year IF } \\
\hline & $O A$ & SA & OA & SA & $O A$ & SA \\
\hline \multicolumn{7}{|c|}{ Years } \\
\hline 1999 & $0.17(0.09)$ & $0.38(0.41)^{*}$ & $0.09(0.19)$ & $0.66(0.84)^{* *}$ & $0.17(0.15)$ & $0.74(0.98)^{*}$ \\
\hline 2000 & $0.21(0.22)$ & $0.39(0.50)^{*}$ & $0.21(0.71)$ & $0.79(1.18)^{*}$ & $0.20(0.55)$ & $0.83(1.09)^{*}$ \\
\hline 2001 & $0.15(0.19)$ & $0.46(0.39)^{*}$ & $0.13(0.63)$ & $0.95(1.13)^{* *}$ & $0.18(0.67)$ & $1.06(1.34)^{*}$ \\
\hline 2002 & $0.16(0.41)$ & $0.49(0.49)^{*}$ & $0.17(0.68)$ & $1.03(1.39)^{*}$ & $0.17(0.82)$ & $1.23(1.47)^{*}$ \\
\hline 2003 & $0.17(0.36)$ & $0.47(0.55)^{*}$ & $0.22(0.71)$ & $1.04(1.45)^{* *}$ & $0.24(0.93)$ & $1.20(1.56)^{*}$ \\
\hline 2004 & $0.15(0.46)$ & $0.49(0.53)^{*}$ & $0.21(0.95)$ & $1.21(1.33)^{*}$ & $0.19(0.83)$ & $1.23(1.52)^{*}$ \\
\hline 2005 & $0.18(0.45)$ & $0.54(0.63)^{*}$ & $0.27(0.99)$ & $1.28(1.51)^{*}$ & $0.31(0.95)$ & $1.35(1.75)^{*}$ \\
\hline 2006 & $0.15(0.43)$ & $0.60(0.62) *$ & $0.22(0.86)$ & $1.31(1.59)^{* *}$ & $0.22(0.99)$ & $1.49(1.71)^{*}$ \\
\hline 2007 & $0.17(0.46)$ & $0.61(0.54)^{*}$ & $0.21(1.07)$ & $1.36(1.49)^{*}$ & $0.22(1.13)$ & $1.45(1.63)^{*}$ \\
\hline 2008 & $0.18(0.48)$ & $0.66(0.72)^{*}$ & $0.26(1.52)$ & $1.47(1.51)^{* *}$ & $0.25(1.39)$ & $1.55(1.59)^{*}$ \\
\hline 2009 & $0.18(0.63)$ & $0.70(0.78)^{*}$ & $0.34(1.43)$ & $1.63(1.61)^{* *}$ & $0.34(1.67)$ & $1.72(1.69)^{*}$ \\
\hline 2010 & $0.18(0.55)$ & $0.72(0.74)^{*}$ & $0.44(1.24)$ & $1.76(1.72)^{*}$ & $0.38(1.56)$ & $1.99(1.70)^{*}$ \\
\hline 2011 & $0.20(0.76)$ & $0.76(0.63)^{*}$ & $0.55(1.56)$ & 1.85 (1.79) & $0.53(1.86)$ & $1.94(1.98)^{*}$ \\
\hline 2012 & $0.22(0.69)$ & $0.71(0.67)$ & $0.78(1.82)$ & $1.97(1.99)^{*}$ & $0.71(1.85)$ & $2.02(2.14)^{*}$ \\
\hline 2013 & $0.22(0.71)$ & $0.86(0.82)$ & $0.73(1.72)$ & $2.02(1.93)$ & $0.71(1.88)$ & $2.19(1.88)$ \\
\hline 2014 & $0.26(1.15)$ & $0.85(0.84)$ & $0.81(1.96)$ & $2.09(1.78)$ & $0.75(2.10)$ & $2.24(1.88)$ \\
\hline 2015 & $0.31(0.80)$ & $0.87(0.76)^{*}$ & $0.74(1.33)$ & $2.00(1.70)^{*}$ & $0.81(1.87)$ & $2.20(1.83)$ \\
\hline 2016 & $0.30(0.45)$ & $0.91(0.76)^{*}$ & $0.65(0.91)$ & $1.87(1.69)$ & $0.74(1.00)$ & $2.19(1.84)$ \\
\hline 2017 & $0.27(0.78)$ & $0.82(0.64)$ & $0.62(1.62)$ & $1.84(1.61)$ & 0.61 (1.49) & $2.17(1.56)$ \\
\hline 2018 & $0.31(0.86)$ & $0.78(0.70)$ & $0.80(2.28)$ & $1.93(1.69)$ & $0.78(2.10)$ & $2.04(1.55)$ \\
\hline
\end{tabular}

OA — open access; SA — subscription access; SJR — SCImago journal rank; JIF — Journal impact factor; IF — Impact factor; $p<0.05$ statistically significant; ${ }^{*} \mathrm{p}<0.05$; ${ }^{* *} p<0.001$ 
Table 2. The data of $h$-index, citations and documents of open access and subscription access journals in the last three years

Table 2A. Comparison of OA and SA journals

\begin{tabular}{|c|c|c|c|c|}
\hline & \multicolumn{2}{|c|}{$O A$} & SA & p \\
\hline Self-Citation & \multicolumn{2}{|c|}{$0.49(1.58)$} & $0.38(1.55)$ & 0.499 \\
\hline Total Citations & \multicolumn{2}{|c|}{$8.58(18.74)$} & 6.25 (20.68) & 0.232 \\
\hline Non-Citable & \multicolumn{2}{|c|}{$0.60(0.95)$} & $0.43(1.36)$ & 0.683 \\
\hline Citable & \multicolumn{2}{|c|}{$9.67(14.21)$} & $4.81(8.03)$ & $<0.001$ \\
\hline Uncited & \multicolumn{2}{|c|}{$5.86(4.26)$} & $2.67(3.51)$ & $<0.001$ \\
\hline Cited & \multicolumn{2}{|c|}{$4.14(8.63)$} & $2.35(5.04)$ & 0.035 \\
\hline H-index & \multicolumn{2}{|c|}{$13.00(22.00)$} & $37.00(65.25)$ & 0.003 \\
\hline \multicolumn{5}{|c|}{ Table 2B. Comparison of OAF, OAP and SA journals } \\
\hline & OAF & OAP & SA & p \\
\hline Self-Citation & $0.30(0.77)$ & $0.90(3.46)$ & $0.38(1.55)$ & 0.211 \\
\hline Total Citations & $2.28(9.21)$ & $16.27(4.55)$ & 6.25 (20.68) & 0.005 \\
\hline Non-Citable & $0.93(1.63)$ & $0.44(0.67)$ & $0.43(1.36)$ & 0.466 \\
\hline Citable & $7.98(10.84)$ & 11.22 (18.74) & $4.81(8.03)$ & 0.001 \\
\hline Uncited & $5.98(4.79)$ & $5.42(5.58)$ & $2.67(3.51)$ & $<0.001$ \\
\hline Cited & $1.93(5.37)$ & 5.62 (63.77) & $2.35(5.04)$ & 0.003 \\
\hline H-index & $10.00(13.00)$ & $26.50(30.25)$ & $37.00(65.25)$ & 0.001 \\
\hline
\end{tabular}

Total citations: OAF vs OAP ( $p=0.001)$, OAP vs SA ( $p=0.004)$; citable: OAP vs SA ( $p=0.001)$; cited: OAF vs OAP ( $p=0.007)$, OAP vs SA ( $p=0.001)$; uncited: OAF vs SA $(p<0.001)$; $h$-index: OAF vs OAP $(p=0.001)$, OAF vs SA ( $p<0.001)$; OA — open access; SA — subscription access; OAF — open access free; OAP — open access paid

and 3-year IF were statistically higher for SA journals in the past years. Recently, even though the SJR, JIF and 3-year IF values have remained high for SA journals, the difference is no longer significant.

The data for h-index, citations and documents of OA and SA journals in the last three years is shown in Table 2. For each group, the total number of self-citations, total citations, non-citable, citable documents, cited and uncited documents are calculated by dividing by the number of journals. With this division, we obtained the values of these data per journal. Citable, uncited and cited documents were statistically higher for OA journals (Tab. 2A). In contrast, the h-index was markedly high for SA journals compared to OA journals (Tab. 2A). We divided OA journals into subgroups according to APC and non-APC and the results of the comparisons for these three groups are shown in Table 2B. When the OA journals were divided and evaluated in two subgroups as OAF and OAP, there was a marked increase in OAP compared to SA journals in terms of total citations, citable and cited documents. Also, the significant difference between $O A$ and $S A$ journals in terms of $h$ index disappeared when OAP and SA journals were compared (Tab. 2).

When we evaluated the fifth and tenth percentile of the journals according to SJR, there was no OA journal in the fifth percentile and there was only one OA journal in the tenth percentile (Tab. 3). In addition, the SJR, JIF, 3-year IF, $h$ index, and the indexing of Web of Science for the fifth and tenth percentile of the journals are shown in Table 3. For the analyzed years, the SJR values of the first five journals in the $\mathrm{OA}$ and SA groups are given in Table 4.

Figure 1 shows the annual percentage changes of SJR, JIF and 3-years IF according to OA vs SA and OAF vs OAP vs $S A$ groups by years. While the number of OA journals was seven (6.9\%) in 1999, the number of SA journals was 95 (93.1\%). By 2018, the number of OA journals had risen to $43(23.5 \%)$ and the number of SA journals to 140 (76.5\%). When the increase in the number of journals between 1999 and 2018 was compared, the statistical significance was in favor of OA journals ( $p<0.001)$. The increase in the number of journals by years is shown in Figure 2. Twenty of the OA journals were receiving APC. The average APC value of OA journals was $\$ 652.63$ (range, \$0-2570). When the OAP journals were evaluated, there was a positive correlation between the SJR and APC for OA journals (correlation coefficient $0.716, r=0.513$, p value: $<0.001$ ) (Fig. 3 ).

\section{DISCUSSION}

In our study, we showed that the SJR, JIF and 3-year IF continued to be significantly higher in SA group journals in most of the analyzed years. However, in recent years, these significant differences disappeared. According to our results, despite the disadvantage of APC of OA journals, it can be 


\begin{tabular}{|c|c|c|c|c|c|c|}
\hline & Group & SJR & JIF & 3-year IF & H-index & WOS \\
\hline \multicolumn{7}{|c|}{ Journals } \\
\hline 1 & SA & 5.172 & 12.919 & 13.484 & 158 & SCI-EX \\
\hline 2 & SA & 3.268 & 5.730 & 5.760 & 203 & SCI-EX \\
\hline 3 & SA & 3.155 & 5.106 & 5.344 & 128 & SCI-EX \\
\hline 4 & SA & 2.616 & 5.720 & 5.902 & 209 & SCI-EX \\
\hline 5 & SA & 2.566 & 3.780 & 4.310 & 201 & SCI-EX \\
\hline 6 & SA & 2.332 & 5.206 & 5.208 & 190 & SCI-EX \\
\hline 7 & SA & 2.126 & 4.221 & 4.367 & 147 & SCI-EX \\
\hline 8 & SA & 2.008 & 3.845 & 3.538 & 83 & $\mathrm{SSCl}$ \\
\hline 9 & SA & 1.968 & 4.505 & 4.489 & 148 & SCI-EX \\
\hline 10 & SA & 1.555 & 2.979 & 3.424 & 104 & SCI-EX \\
\hline 11 & SA & 1.523 & 2.410 & 2.748 & 92 & SCI-EX \\
\hline 12 & SA & 1.390 & 3.140 & 3.523 & 82 & SCI-EX \\
\hline 13 & $\mathrm{OA}$ & 1.389 & 2.645 & 3.026 & 66 & SCI-EX \\
\hline 14 & SA & 1.369 & 2.910 & 2.894 & 92 & SCI-EX \\
\hline 15 & SA & 1.340 & 3.151 & 3.483 & 120 & SCI-EX \\
\hline 16 & SA & 1.338 & 3.670 & 3.479 & 20 & SCI-EX \\
\hline 17 & SA & 1.336 & 3.160 & 3.516 & 100 & SCI-EX \\
\hline 18 & SA & 1.331 & 3.350 & 3.249 & 51 & SCI-EX \\
\hline
\end{tabular}

OA — open access; SA — subscription access; SJR — SCImago journal rank; JIF — Journal impact factor; IF — Impact factor; WOS — Web of Science; SCI-EX — Science citation index expanded; $\mathrm{SSCl}$ - Social sciences citation index

said that the increase in impact factors of $O A$ journals has been higher than SA journals in recent years. Moreover, these findings support the hypothesis proposed at the beginning of the study.

In the literature, there is limited data on the comparison of SJR and other values in the SCImago database and no data in terms of OA and SA journals in the field of obstetrics and gynecology. Polat et al. [18], studied data from orthopedics journals in the SCImago database between 1999-2017, which was published in 2019. They compared 52 OA and 197 SA journals and reported a significant increase in the total number of journals between 1999-2017 and the number of citable documents and total citations in the last three years in favor of OA [18]. In their study, they also found a significantly different increase in three years IF between 2014 and 2017 for OA journals, but not for SA journals [18]. Unlike Polat et al. [18], we assessed the data for self-citation, total citations, non-citable and citable documents, uncited and cited documents per journal. We found a statistically significant difference in OA journals compared to SA journals in terms of citable, cited and uncited documents. In our study, total citations were statistically higher when we formed OAF and OAP subgroups for OA journals. The increase in total citations was in favor of OAP compared to OAF and SA. Also, in this study, while the average of non-citable documents was significantly high in SA journals when taken without dividing per journal, this significance disappeared when non-citable documents per journal were calculated. In addition, while there was no significance between the $O A$ and SA groups when the average of the cited documents was calculated, it was significant when the cited documents per journal was calculated.

Citation is the most important constituent used to determine the impact factor of a journal. However, in recent years, new assessment factors have been employed that not only take into account the number of citations to a journal, but also the effect of the citations as well as the importance of the actors making those citations. The SJR is a prestige indicator that is used to calculate the scientific effectiveness of a journal, taking into account the number of citations to the journal and the prestige of the journal in which the cited publication is published. The value of SJR is, in their own words, based on the idea that 'all citations are not created equal'. It also measures the scientific impact of the average article in a journal and the relevance of articles published in the journal to global scientific discussions [17]. In 2014, Jamali et al. [19], investigated the factors affecting the SJR of obstetrics and gynecology journals indexed in the Scopus database between 1999-2013 and they noted that citations per document and citable documents per document in 


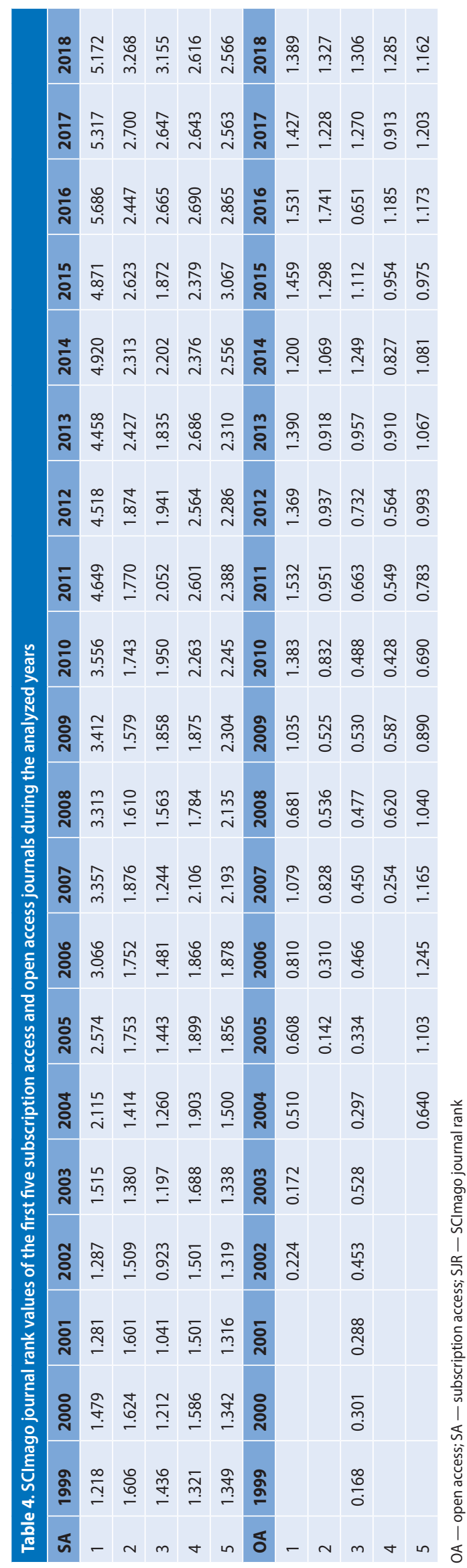

a 3-year period affected SJR values, but they did not distinguish the journals as either OA or SA.

In a review published in 2017, it was stated that OA journals in the field of health reached similar or higher citation levels and scientific value than SA journals [20]. This finding has also been supported by other studies [21, 22]. In our results, the SJR, JIF and 3-year IF percentage changes remained stable for SA journals, whereas for OA journals (especially for OAP), these parameters showed progress with deep fluctuations, as shown in Figure 1. In OAP journals, SJR and 3-year IF were statistically higher compared to SA in recent years, but this difference was not observed for JIF. In the light of these data, it can be said that our study confirms the findings of previous literature.

According to Harnard, the first scholarly OA journal in the broadcasting industry was published in 1989 [23]. In recent years, the tendency to convert publishing policies into open access has been increasing and the percentage of $O A$ journals among all journals is rising Several months before this study was prepared for publication, five obstetrics and gynecology journals in the SCImago database changed their publication policies and switched from subscription access to open access, which provides support for our hypothesis. We showed that between 1999 and 2018, the numbers of OA and SA journals that indexed in SClmago database in the field of obstetrics and gynecology increased. While there was a 13.5-fold increase for OA journals, it was approximately 1.5 -fold in SA journals $(p<0.001)$. The increase in the number of $O A$ journals over time has been demonstrated in other publications $[18,24]$.

We found a strong positive correlation between the APC and SJR of OAP journals. Likewise, Yuen et al. [25], achieved similar results in their study. This positive correlation was also demonstrated by Polat et al. [18]. However, at this point, it is necessary to express caution regarding predatory journals, because in the publishing industry, the number of predatory journals is increasing since the majority of $O A$ journals are paid for through APC [26]. There is no universally accepted definition for predator journals; in fact, they can be defined as journals that collect funds from authors but provide inadequate and poor quality editorial services. However, this should not be generalized to all OA journals. In addition to those journals that do not receive publication fees, journals indexed in reputable databases with high impact factors and high-quality publications should not be considered in this category, even if they receive publication fees. Therefore, these issues are important and should be taken into consideration by authors when choosing a journal to which they will submit an article.

In this study, the records of the SCImago and WOS databases have been discussed. Since these databases are open to the public, this eliminates the possibility of bias in the examined data. In the whole study, most of the data have 


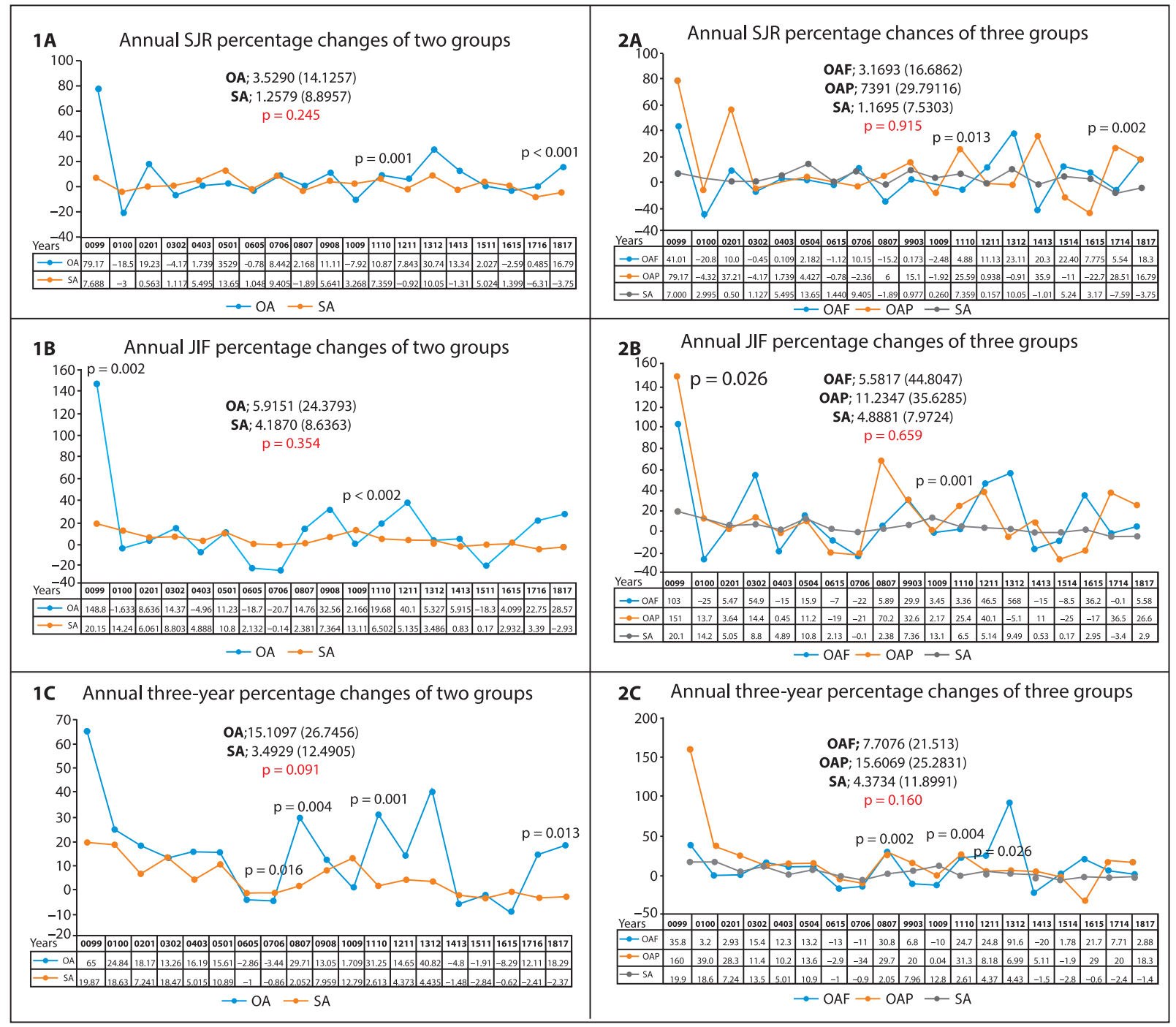

Figure 1. Annual percentage changes of SCImago journal rank (SJR), Journal impact factor (JIF), 3-year Impact factor (IF); 1A. Annual SJR percentage of two groups; 1B. Annual JIF percentage of two groups; 1C. Annual 3-year IF percentage of two groups; 2A. Annual SJR percentage of three groups; 2B. Annual JIF percentage of three groups; 2C. Annual 3-year IF percentage of three groups; OA - open access; SA - subscription access; OAF — open access free; OAP — open access paid; Years indicate the percentage change between two consecutive years

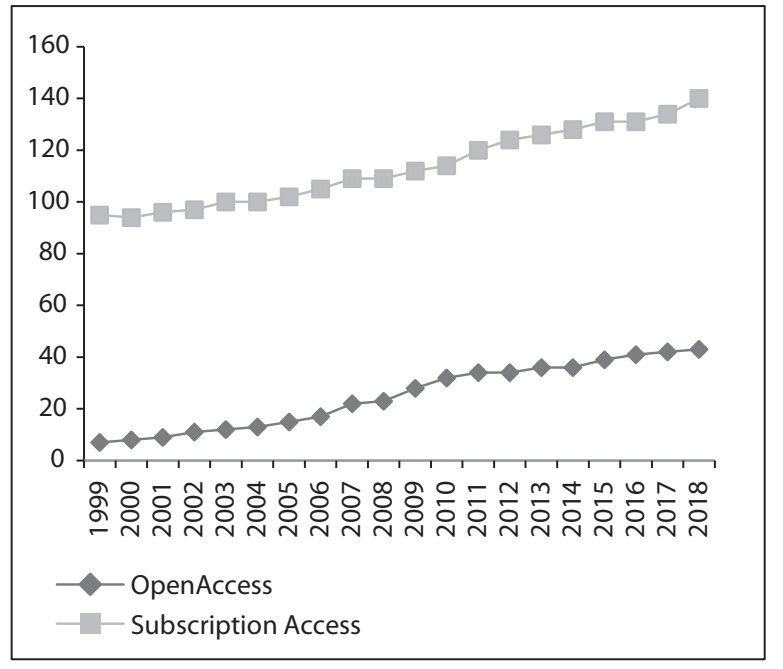

Figure 2. The increase in the number of journals by years

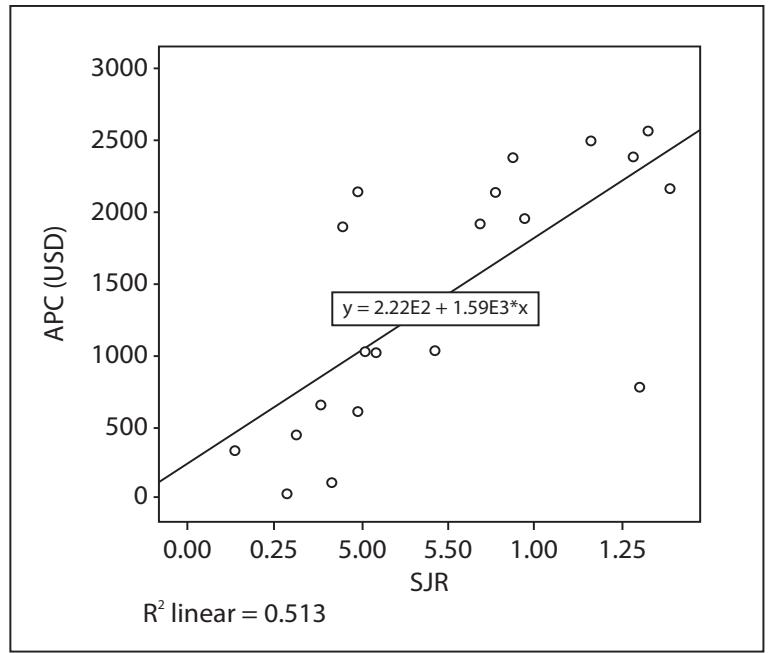

Figure 3. The correlation between SCImago journal rank and publication fees in open access paid journals. APC — authors, publication fees; SJR — SClmago Journal Rank 
specifically been recorded for recent years, while only some of the data have been recorded for all years in the system. This policy was adopted on the basis of our hypothesis that the upward trend in the measurements of OA journals has increased in recent years. The fact that SA journals offering OA options were not specified in this study is considered as a limitation. Also, the limited number of OA journals can be considered as another limitation for this study.

\section{CONCLUSIONS}

In conclusion, access to information has become easier as a result of technological development and this will continue to affect the access policies of journals. Even though OA journals have the disadvantage of APC, the parameters that show the scientific values of the journals have been increasing rapidly for OAP journals in recent years. The rise of open access journals in terms of number and quality is likely to continue. The recent increase and results of studies in this field also support this view.

\section{Acknowledgements}

The authors declare no financial relationship with any organization. The authors have full control over all primary data.

\section{Conflict of interest}

No potential conflict of interest was reported by the authors.

\section{REFERENCES}

1. Laakso $M$, Welling $P$, Bukvova $H$, et al. The development of open access journal publishing from 1993 to 2009. PLoS One. 2011; 6(6): e20961, doi: 10.1371/journal.pone.0020961, indexed in Pubmed: 21695139.

2. Davis PM, Lewenstein BV, Simon DH, et al. Open access publishing, article downloads, and citations: randomised controlled trial. BMJ. 2008; 337: a568, doi: 10.1136/bmj.a568, indexed in Pubmed: 18669565.

3. Moorhead LL, Holzmeyer C, Maggio LA, et al. In an Age of Open Access to Research Policies: Physician and Public Health NGO Staff Research Use and Policy Awareness. PLoS One. 2015; 10(7): e0129708, doi: 10.1371/journal.pone.0129708, indexed in Pubmed: 26200794.

4. Maggio LA, Moorhead LL, Willinsky JM. Qualitative study of physicians' varied uses of biomedical research in the USA. BMJ Open. 2016; 6(11): e012846, doi: 10.1136/bmjopen-2016-012846, indexed in Pubmed: 27872121.

5. Ottaviani J.The Post-Embargo Open Access Citation Advantage: It Exists (Probably), Its Modest (Usually), and the Rich Get Richer (of Course). PLoS One. 2016; 11(8): e0159614, doi: 10.1371/journal.pone.0159614, indexed in Pubmed: 27548723.

6. Piwowar $\mathrm{H}$, Priem J, Larivière $\mathrm{V}$, et al. The state of $\mathrm{OA}$ : a large-scale analysis of the prevalence and impact of Open Access articles. PeerJ. 2018; 6: e4375, doi: 10.7717/peerj.4375, indexed in Pubmed: 29456894.
7. Wang X, Liu C, Mao W, et al. The open access advantage considering citation, article usage and social media attention. Scientometrics. 2015; 103(2): 555-564, doi: 10.1007/s11192-015-1547-0.

8. Barbour V, Chinnock P, Cohen B, et al. The impact of open access upon public health. Bull World Health Organ. 2006; 84(5): 339, doi: 10.2471/blt.06.032409, indexed in Pubmed: 16710533.

9. Tennant JP, Waldner F, Jacques DC, et al. The academic, economic and societal impacts of Open Access: an evidence-based review. F1000Res. 2016; 5: 632, doi: 10.12688/f1000research.8460.3, indexed in Pubmed: 27158456.

10. Rupp M, Anastasopoulou L, Wintermeyer E, et al. Predatory journals: a major threat in orthopaedic research. Int Orthop. 2019; 43(3): 509-517, doi: 10.1007/s00264-018-4179-1, indexed in Pubmed: 30288548.

11. Beall J. What I learned from predatory publishers. Biochem Med (Zagreb). 2017; 27(2): 273-278, doi: 10.11613/BM.2017.029, indexed in Pubmed: 28694718.

12. Garfield E. The History and Meaning of the Journal Impact Factor. JAMA. 2006; 295(1): 90, doi: 10.1001/jama.295.1.90.

13. González-Pereira B, Guerrero-Bote V, Moya-Anegón F. A new approach to the metric of journals' scientific prestige: The SJR indicator. Journal of Informetrics. 2010; 4(3): 379-391, doi: 10.1016/j.joi.2010.03.002.

14. Scimago Research Group, 2007. Description of SCImago Journal Rank Indicator. https://www.scimagojr.com/SCImagoJournalRank.pdf (26.08.2020).

15. https://clarivate.com/webofsciencegroup/essays/impact-factor/ (26.08.2020).

16. https://www.scimagojr.com/journalsearch.php?q=15623\&tip=sid\&clean $=0 .(26.08 .2020)$

17. McDonald K. Physicist Proposes New Way to Rank Scientific Output. PhysOrg. (8 November 2005) 26.08.2020.

18. Polat B, Özmanevra R, Özmanevra PT, et al. Comparison of the impact factors of subscription access and open access orthopedics and sports medicine journals in the SCImago database. Eklem Hastalik Cerrahisi. 2019; 30(2): 163-167, doi: 10.5606/ehc.2019.64729, indexed in Pubmed: 31291866.

19. Jamali J, Salehi-Marzijarani M, Ayatollahi SM. Factors Affecting Journal Quality Indicator in Scopus (SCImago Journal Rank) in Obstetrics and Gynecology Journals: a Longitudinal Study (1999-2013). Acta Inform Med. 2014; 22(6): 385-388, doi: 10.5455/aim.2014.22.385-388, indexed in Pubmed: 25684846.

20. Erfanmanesh M. Status and quality of open access journals in Scopus. Collection Building. 2017; 36(4): 155-162, doi: 10.1108/cb-02-2017-0007.

21. Björk BC, Solomon D. Open access versus subscription journals: a comparison of scientific impact. BMC Med. 2012; 10: 73, doi: 10.1186/17417015-10-73, indexed in Pubmed: 22805105.

22. Atayero AA, Popoola SI, Egeonu J, et al. Citation analytics: Data exploration and comparative analyses of of Open Access and Subscription-Based publications indexed in (2014-2016). Data Brief. 2018; 19 198-213, doi: 10.1016/j.dib.2018.05.005, indexed in Pubmed: 29892634.

23. Harnad S. Free at last: the future of peer-reviewed journals. D-Lib Magazine December. 1999; 5: 12.

24. Kazikdas KC, Tanik M, Ural A. Changing trends in otorhinolaryngology publishing. Acta Otorhinolaryngol Ital. 2020; 40(1): 1-4, doi: 10.14639/0392-100X-2192, indexed in Pubmed: 30933183.

25. Yuen J, Muquit S, Whitfield PC. Correlation Between Cost of Publication and Journal Impact. Comprehensive Cross-sectional Study of Exclusively Open-Access Surgical Journals. J Surg Educ. 2019; 76(1): 107-119, doi: 10.1016/j.jsurg.2018.06.029, indexed in Pubmed: 30100322.

26. Shen C, Björk BC. 'Predatory' open access: a longitudinal study of article volumes and market characteristics. BMC Med. 2015; 13: 230, doi: 10.1186/s12916-015-0469-2, indexed in Pubmed: 26423063. 